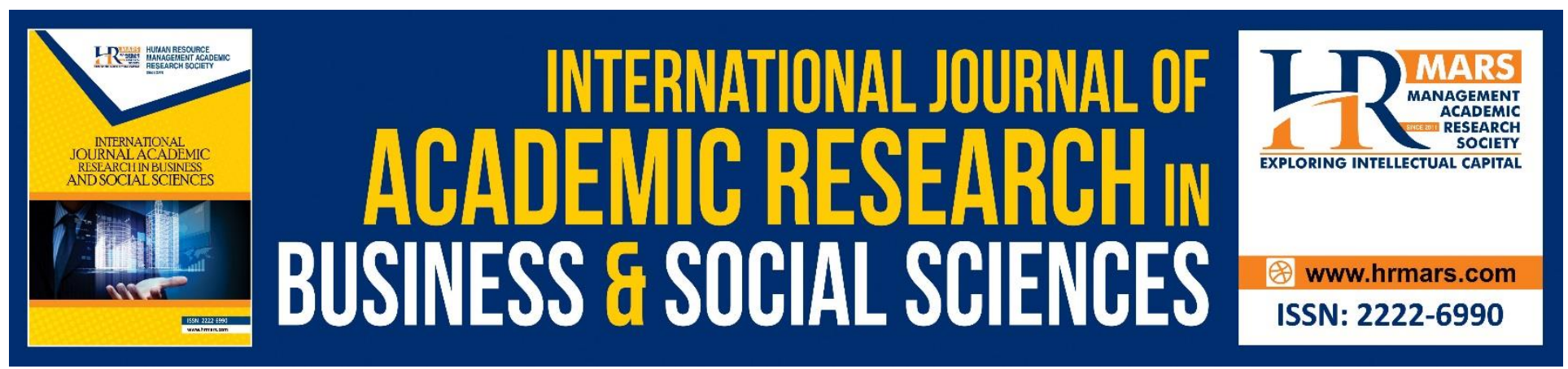

\title{
General Purpose Technologies: Characteristics And Impact On Economic Growth
}

Antonella Laino

To Link this Article: http://dx.doi.org/10.6007/IJARBSS/v9-i2/5611

DOI: $\quad 10.6007 /$ IJARBSS/v9-i2/5611

Received: 12 Feb 2019, Revised: 03 March 2019, Accepted: 08 March 2019

Published Online: 13 March 2019

In-Text Citation: (Laino, 2019)

To Cite this Article: Laino, A. (2019). General Purpose Technologies: Characteristics And Impact On Economic Growth. International Journal of Academic Research in Business and Social Sciences, 9(2), 734-748.

Copyright: (C) 2019 The Author(s)

Published by Human Resource Management Academic Research Society (www.hrmars.com)

This article is published under the Creative Commons Attribution (CC BY 4.0) license. Anyone may reproduce, distribute, translate and create derivative works of this article (for both commercial and non-commercial purposes), subject to full attribution to the original publication and authors. The full terms of this license may be seen at: $\underline{\text { http://creativecommons.org/licences/by/4.0/legalcode }}$

Vol. 9, No. 2, 2019, Pg. 734 - 748

http://hrmars.com/index.php/pages/detail/IJARBSS

JOURNAL HOMEPAGE

Full Terms \& Conditions of access and use can be found at http://hrmars.com/index.php/pages/detail/publication-ethics 


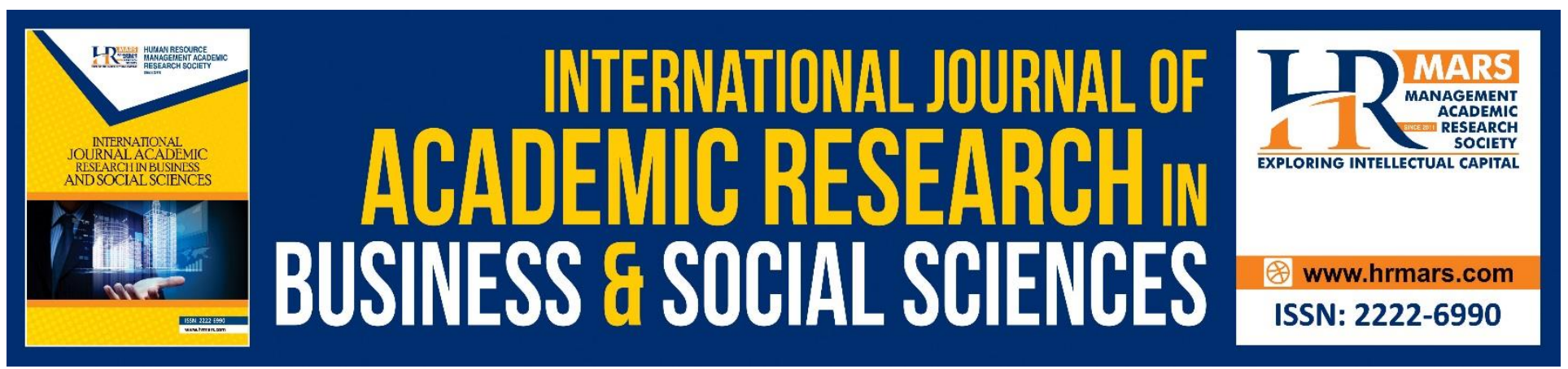

\title{
General Purpose Technologies: Characteristics And Impact On Economic Growth
}

\author{
Antonella Laino \\ e-Campus University, Como, Italy \\ Email: antonella.laino@uniecampus.it
}

\begin{abstract}
In every 'era' innovations emerge which, due to the specific characteristics that distinguish them, have enormous impacts on the global economic system for a long period of time. Under specific conditions, these "radical" innovations are called general purpose technologies (GPT).

The present work investigates the essential characteristics of radical innovations, bringing out the elements that make such innovations disruptive with respect to the current economic paradigm. Then it analyzes the specific characters of the GPT, in order to establish which of the major radical innovations in history can actually be defined as GPT.

After having analyzed some of the most important economic models on GPT, we proceed with the analysis of the impact that these innovations have on the process of economic growth, constantly referring to the empirical evidence of the most recent studies
\end{abstract}

Keywords: Radical Innovation, General Purpose Tecnologies, Innovation, ICT

\section{INTRODUCTION}

Each era is distinguished by the emergence of particular technological innovations, which have an impact on the economy and on development for long periods of time. These drastic innovations induce a series of significant changes on the economic and social system, also giving rise to many incremental innovations. These particular technologies are usually usable in a large number of sectors with a wide range of applications. Very often these innovations represent the tool for restarting an economy that has reached a level of maturity such as not to achieve more significant increases in productivity. But what is the impact of such disruptive innovations on the growth process?

In the paper, after having introduced the theme of radical innovations and demonstrated the substantial coincidence between these and the general purpose technologies (GPT), the distinctive features of GPT will be investigated in order to examine the main study models to link the introduction of GPT to the process of economic growth. 


\section{RADICAL INNOVATIONS}

Radical innovation is considered the true engine of activation of long-term growth; already in the twenties of the last century Schumpeter highlighted the importance of this type of 'disruptive' innovation for business success and the growth of the economy. In fact, the 'creative destruction' to which Schumpeter refers (1934) is a radical revolution, even if there is no real distinction in the work of the economist between radical innovations and other types of innovations.

Sometimes the scope of a radical innovation is linked to the nature of the ideas on which the innovative activity is based, the extent to which codified information or tacit knowledge are involved in the creation of such innovation. The innovative activity based on economic information tends to be of an incremental nature because it generally implies an organizational consensus on the potential value and impact of innovation. In other words, incremental innovation, unlike radical innovation, tends to support and improve the organization currently in place (Dahlin, Behrens, 2005).

Radical innovation, on the other hand, is based on tacit knowledge, difficult to codify, whose economic value remains uncertain and asymmetrical. In fact, the expected value of a new idea is very uncertain and has a greater variance than would be associated with innovative information-based activity. When it comes to radical innovation, there is uncertainty as to whether the new service or product can be realized, on what are the production and delivery methods, if sufficient demand can be created: in other words, these are elements of strong uncertainty on the actual realization of the idea (Arrow, 1962).

Again, the tacit knowledge on which radical innovation is based is affected by considerable asymmetries, since the company that has to bear the burdens for the realization may not be able to a priori evaluate the potential of the new idea having to, to this end, relying on the skills and experience of a subject outside the organization. Therefore differences in terms of knowledge and competence can lead to different assessments of the expected value of a new project or to the variation of the results expected from the realization of the new idea. Normally radical innovations are the result of a long and intense formalized R\&D activity, generally typical of larger companies.

As we know, the innovative activity and the research that supports it are very onerous activities, which lead to the sustaining of considerable quotas of fixed costs, often irrecoverable; moreover, the $R \& D$ process often leads to economies of scale. These two elements are already sufficient to attribute the processes of development of radical innovations to large companies (Cohen, Klepper 1992).

Large companies, that is, those that manage to achieve market power, even if only temporarily, will choose radical innovation as a tool for maximizing results, because the company's ability to appropriate the economic returns deriving from R\&D, and in general from all investments aimed at generating knowledge, is directly related to the measure of market power that the company can exercise (Kamien, Schwartz, 1975).

Last but not least, R\&D is a very risky activity, difficult to deal with independently by small businesses, also because a small company that faces an uncertain and long search path, investing most of its resources in a single project makes itself very vulnerable. On the contrary, the large company can reduce the risk deriving from the innovative activity by simultaneously financing diversified research projects, with different risk profiles and expected returns. Furthermore, a large company is facilitated in the concrete applicability of innovation (Nelson, 1959). 
Often the economies of scale associated with production, typical of large companies, can generate economies of scope that make innovative activity conducted by large organizations even more profitable. Economies of scale in promotion, and in distribution, facilitate the penetration of markets by new products, allowing large companies to enjoy a greater potential profit. Furthermore, an innovation that leads to cost reductions allows a relatively higher profit margin to be achieved for the large company. Empirical evidence also supports this position by arguing that technological change is positively correlated with the company dimension (Acs, Audretsch, 2003).

An innovation to be defined as radical must have the character of novelty, uniqueness and considerable impact on the development of future innovations, opening new fields of study and making dominant technologies obsolete: in other words it must turn the status quo upside down.

It is precisely from the very nature of radical innovation that characters emerge that must be present within a company that wants to develop this type of innovation.

Radical innovations derive from the creation of new knowledge, and from the development and marketing of completely new products, sometimes aimed at satisfying new needs. The role of the subjects involved in the process, and their ability to imagine the future of technology, so as to generate completely new ideas that activate radical innovation, becomes fundamental.

The ability to successfully develop and market radical innovations constitutes a dynamic capacity, difficult to develop and to imitate. Dynamic capabilities allow management to adapt, integrate and implement internal and external organizational skills, so as to appropriately allocate resources, skills and functions to adapt to constantly changing environments (Eisenhazdt, Martin, 2000).

Let us briefly recall that the dynamic capabilities approach analyzes the knowledge management processes starting from the notion of Penrose, which defines the company as a repository of knowledge. This approach links competitive advantage to the continuous development of skills, and to the new configuration of its resources and its idiosyncratic capabilities. In other words, the company must be a knowledge-creating organization and not just knowledge-using. And if it is true that even empirical evidence supports the fact of a better performance of radical innovations than incremental ones, it is also true that it is very difficult to develop such innovations (Rubera, Kirca, 2012).

The introduction of new products with a high level of novelty, typical of radical innovations, is positively influenced by the use of formalized innovation processes, by the presence of highly developed and efficient systems for the development of new products, by the existence of alternative processes, and parallels, to innovate in a radical way, ie processes not the line with commonly followed procedures. It has also been noted that companies that implement radical innovations implement a real innovation strategy and define strategic corporate mission and objectives in terms of innovation (Dabrowska et al., 2013).

The development of radical innovations is positively influenced by the opening of the company towards internal and external collaborations. In other words, it is necessary to share knowledge within the organization and to collaborate with external units from which it is possible to draw important insights and new knowledge (Trott, 2009).

The radical innovations of which they have synthesized the characters are often and rightly attributed to the concept of General Purpose Technologies, with which they share the essential characteristics 
INTERNATIONAL JOURNAL OF ACADEMIC RESEARCH IN BUSINESS AND SOCIAL SCIENCES

Vol. 9, No. 2, Feb, 2019, E-ISSN: 222 2-6990 @ 2019 HRMARS

and the paths of development, in addition to the preconditions of birth. We will talk about these in detail in the next sections.

\section{THE GENERAL-PURPOSE TECHNOLOGIES}

Lipsey et al. (2005) define the general purpose technology (GPT)'..a single generic technology, recognizable as such over its whole lifetime, that initially has much scope for improvement and eventually comes to be widely used, to have many uses, and to have many spillovers effect'.

The coincidence, or almost, between the concept of GPT, that of radical innovation and macroinnovation (Mokyr, 1990), or of a change in the technological paradigm (Dosi, 1982) is clear. GPTs are shocks that revitalize the economy in a phase in which it tends to "relax" in a steady-state equilibrium. Normally this technology emerges thanks to the interaction of localized and direct knowledge with the exploitation of technological opportunities and coordination of production through heterogeneous industries and evolving companies.

In every economic era there are technological innovations, such as electricity, transistors, which have an extended and prolonged impact and these drastic innovations lead to a series of secondary incremental innovations. For example, the introduction of the transistor has triggered sequential innovations such as the integrated circuit or the microprocessor, which are used in a large number of sectors, with just as many repercussions in terms of specific incremental innovations.

GPT act as enabling mechanisms for complementary innovations, the development of which leads to a transformation of the economic system and a general increase in productivity.

It is a technology of general applicability, performing a generic function essential for a wide range of products and / or production systems. Furthermore, GPTs are extremely dynamic from a technological point of view, as the continuous innovative efforts increase over time the efficiency of execution even of generic functions, to the benefit of existing and future users, with attention also from other sectors that are encouraged to adopt the new technology (Breshnahan, 2012).

It is a technology of general applicability, performing a generic function essential for a wide range of products and / or production systems. Furthermore, GPTs are extremely dynamic from a technological point of view, as the continuous innovative efforts increase over time the efficiency of execution even of generic functions, to the benefit of existing and future users, with attention also from other sectors that are encouraged to adopt the new technology (Breshnahan, 2012).

These technologies show significant innovative complementarities with the application sectors, ie the technical advances of GPT make subsequent innovations and the improvement of existing technologies more profitable (Rosenberg, Trajtenberg, 2004).

From the input point of view what makes a technology general purpose is its general applicability, the technological dynamism and the predisposition to the creation of further innovation. From the point of view of output there is a slowdown in productivity, an increase in the demand for skilled and qualified labor, a reallocation of resources, an initial decline in stock prices, a change in the relative market shares of individual companies, and a deterioration in the trade balance.

The slowdown in productivity is due to the learning effect and the need to allocate new resources for the development of the GPT. This highlights the existence of a time gap necessary both to acquire knowledge and skills necessary for the best exploitation of the new technology, and to reallocate the 
resources necessary for procuring new capitals compatible and complementary to the exploitation and use of GPT.

The gap that emerges for the learning phase also highlights a demand for new workforce, that is employees with qualifications and knowledge compatible with the application of new technology to business processes.

As mentioned, the available resources are reallocated, dedicating them in part to the development of the skills necessary for the use of the new technology, and partly to replace the old capital goods with new assets that allow the exploitation of all the potentialities expressed by the GPT. Sometimes this also leads to a reorganization of the entire company, with inputs and outputs from the industry or with integration operations with other companies.

The initial fall in share prices is due to the acceleration of the process of obsolescence of capital goods caused by the adoption of the GPT(Anghion, Howitt, 1998).

The positions of companies in the market are called into question by the introduction of a GPT as the relative quotas are usually changed in favor of younger companies, which are more receptive and capable of adaptation than those already established in the market.

Finally, there is an initial worsening of trade balances because the reallocation of activities and the temporary reduction of production push demand and consumption towards new foreign markets (Leifer et al, 2000).

In particular, the slowdown in productivity and the time required for this to return to the preintroduction levels of GPT, overcoming them, can be read as a possible explanation for the Solow paradox (Basu, Fernald, 2007). Referring to the paradox Jacobs-Nahuis (2002), they present a model according to which the introduction of a new GPT leads to a reduction in production in the short term, as the most qualified workers are removed from production and dedicated to more profitable activities such as research, in order to make them more productive.

\section{GPT CHARACTERISTICS}

One of the fundamental characteristics of a GPT is its pervasiveness (pervasiveness) which implies that this technology is used for a wide range of products and in various and distinct applications.

A GPT has a decisive impact on technological change and productivity growth in a large number of industries (Jovanovic, Rousseau, 2005). The pervasiveness determines a use of technology in almost all sectors and this becomes the input of many industries even with different characters, even if not in all sectors the speed of diffusion is identical, depending on the presence of complementary factors (Beaudry et al, 2010).

Furthermore the adoption and use of the new technology is gradual and for some time new technology and old technology coexist. We could therefore define pervasiveness as the potential broader application of general purpose technology in a wide range of economic areas. In fact the introduction of a GPT in a sector allows to generate, within the same, new processes and complementary innovations that further increase the returns to scale (Bresnahan, Trajtenberg, 1995).

Another essential characteristic is technological dynamism, which postulates that general purpose technology significantly improves during its useful life. This dynamism involves an evolution of 
technology both in time and space; a low marginal reproduction cost, and a high modeling of the technology and its applications on the needs of the user (Park et al. 2007).

Finally, even if not less important, the complementarity (dual inducement mechanism) which indicates that the improvements trigger an innovative process in the sectors in which this technology is introduced and vice versa (Helpman, 1998).

With regard to GPT, various forms of complementarity have been analyzed: complementarities with a cluster of technologies define and support GPT as in the case of computers that are used in the production of new chips that allow productivity improvements in other digital devices; complementarity with a cluster of enabling technologies, which make it possible to identify technological complementarities that go beyond the technologies that define them, activating new processes of invention and innovation, many of which were technically or economically impossible without enabling GPT, but which are not part of the GPT.

In this regard, reference can be made to the electricity that allowed the development of electronic devices, which allow the use of the Internet. There is also talk of complementarity with a cluster of technologies that transform society, politics and the economy. With the expansion of the uses of a GPT the technologies involved have effects, sometimes very important, on the economic and social structure of a country and this implies changes, but also the emergence of new opportunities (Carlaw, Lipsey, 2002).

The complementarities created by GPT concern many applications that are unique, that is, no other combination of technologies can produce that specific application, and without it the whole system would not work: in other words there are no close substitutes. For example, there is no valid alternative to electricity for most contemporary technologies, which are powered by this and would not exist without it.

If a technology evolves in such a way as to possess these three characteristics, pervasiveness, technological dynamism and complementarity, it is a GPT and this is determined by its nature, which defines its potential, its interaction with other technologies, which determines the extent of the effects which will have, technological efficiency, which helps define the breadth of technology adoption.

These three characters are based on the implicit consideration that GPT is a prevalent technology, that it is present in the system for a long period of time and that it is accepted on a large scale, so as to 'permeate' the entire economic system by improving its performance and triggering new innovative processes.

The prevalence of a technology is determined by its persistence over time, which makes it difficult for alternative technologies to overcome it. In other words, at least for a certain period of time, it must be incontestable. According to David (1987) prevalence is the result of a coordination of agents' choices on a specific technology. And the agents are led to coordinate their choices and, consequently, to create persistence when there is a technical correlation of the components of the system, when the investments are almost irreversible, determining strong switching costs, when there are positive externalities, and in the presence of economies of scale.

The technical interrelation of a system seems to be a very particular character: that is, it is the chemical and / or physical laws, or the engineering relationships that determine this character; therefore the explanation of prevalence is essentially technical. But this interrelation, and the high 
burdens necessary for the exploration of new laws of basic knowledge, explain the presence of high switching costs and, therefore, the prevalence of a given technology for long periods.

The presence of increasing returns can arise both on the supply side and on the demand side.

On the supply side, it was born as a result of learning, learning by using and learning by doing. The latter makes it possible to make a given technology more efficient if it is increasingly used: it therefore supports the competitiveness and persistence of the dominant technology domain.

On the demand side, the presence of increasing returns is explained by the phenomenon of positive network externalities, which increase the positive effects of a technique, or a product, as the number of users increases.

The positive effects of the network, linked to the adoption of a technology by customers, are based on the idea that the individual advantage enjoyed by the subject depends positively on the number of other customers using the same technology, as is the case for telephony, or for the software. And, at least in part, it protects the technology from possible "invasions" of alternative technologies.

Thus, the irreversibility of investments, and increasing returns, indicate that prevalence is dynamically present throughout the lifetime of the technology.

An element underlying the very name of GPT is the fact that it is applied at a general level, both "widely used" (Breshahan, Yin, 2010).

Therefore, GPTs appear as drastic innovations characterized by pervasive use, innovative complementarity and high intrinsic potential for technological improvement (Bresnan, Trajenberg, 1995).

The empirical evidence shows that the GPT diffusion model is very similar to the diffusion model of specific technologies, and can be represented with the note curve with trend to "S". During the diffusion process these innovations could generate growth fluctuations and even real economic cycles. Very often it takes years for a GPT to have a decisive impact on economic aggregates (David, 1990).

Helpman-Trajtenberg (1998) believe that the introduction of a new GPT leads to the birth of a new economic cycle as the technology is to be considered exogenous, and is not used immediately in the most productive way possible. To achieve this goal it is necessary to invent a sufficiently large number of complementary components: for example, software is essential in order to exploit the full potential of the hardware, and is therefore an essential complementary component.

This process, however, is not instantaneous, but requires that resources be diverted from the directly productive sector to that of $R \& D$, with a consequent temporary reduction in production. As soon as a sufficient number of complementary innovations have developed, GPT is used in its full potential for the production of final goods, leading to new growth in productivity.

\section{GPT AND ECONOMIC MODELS: BRIEF ANALYSIS}

In the Hall-Trajtenberg model (2004), GPTs arrive in the economic system in a deterministic way, at predefined time intervals of equal length, generating a symmetrical cycle articulated in two or three sub-phases. In the first phase, the old GPT is used for production, while the resources and the workforce are allocated to enhance the research and development function to obtain new components for the new GPT. 
INTERNATIONAL JOURNAL OF ACADEMIC RESEARCH IN BUSINESS AND SOCIAL SCIENCES Vol. 9, No. 2, Feb, 2019, E-ISSN: $2222-6990$ ๑ 2019 HRMARS

In the second phase, the development of complementary components continues, but new technology is also being adopted, which promotes productivity gains. During the first phase of the cycle real GDP shrinks, because the fees for the most qualified workers needed to implement the new technology increase. This mechanism is well represented by the phrase "time to sow and time to reap" (Helpman, Trajtenberg, 1998)

Anghion-Howitt (1998) highlight how the model illustrated above does not fully represent the empirical evidence of the collapse of values in the first phase of the cycle. In fact, in the HallTrajtenberg model the decline in production is entirely attributed to the transfer of the workforce from the production function to the R\&D function, but considering that on average R\&D workers are only $2.5 \%$ of the workforce, it is difficult accept this explanation and justify a change in aggregate production.

The Anghion-Howitt model adds elements of empiricism to the adoption process, inserting the theme of social learning, in evolutionary terms, imitation. The model divides the cycle into three phases. It is believed that first of all the GPT must emerge at the level of the general economy, then a company in the sector must acquire the template on which to base the experimentation. Finally, the template must be used to identify how to implement GPT in the specific sector. In other words, a significant role is assigned to social learning.

The transition from phase one to phase three requires the reallocation of resources, especially human resources, to research activities, but the model also considers the differentials of competence, the problem of wage disparities and the relationship that technological changes and the effect of innovative wave have on the obsolescence of capital.

The models we have briefly discussed are first-generation models, which share a common hypothesis: GPT is recognized ex-ante as a general-purpose technology and it is this breadth of use that encourages the sectors in which an application potential is recognized to identify and exploit complementarities, starting a double incentive mechanism. Sometimes this condition appears an excessive simplification in an environment where the changes are continuous and sudden, with a high competition, and with selection and diffusion processes that develop in uncertain environments, with high entrepreneurial risk (Arthur, 1989).

Among the second generation models we recall the model by Zon et al (2003) which represents a modification of the Romer model based on the assumption that GPTs are identified ex-ante. It is the first model that considers, and admits, the coexistence of several GPTs. The model identifies two types of R\&D processes, both stochastic: a basic R\&D sector, which produces core GPT technologies, and an applied R\&D sector that produces components.

In both sectors there are diminishing returns, so after the arrival of a core technology the economic incentive shifts, as does the workforce, towards the production of components and complementary ones. The novelty of the model lies in the fact that there is the possibility that some cores represent a failure of the GPT, and this highlights that, during the innovation process, the actual pervasiveness of an innovation, the time of arrival and the actual potential they cannot be identified ex-ante. So the technology is GPT only ex-post, when you know that it can be used in a large number of different uses.

Carlaw - Lipsey (2006) expand the Zon model, hypothesizing the presence of three out-of-equilibrium sectors in which the arrival of a GPT is guided by an endogenous mechanism. The three sectors 
concern a sector in which research accumulates basic knowledge and produces GPT, an applied research sector and a sector that produces consumer goods with a level of productivity that derives from a part of the knowledge generated by applied research.

This accumulation of knowledge depends on the knowledge accumulated in the field of basic research. The latter sector creates basic knowledge related to GPT with a productivity that depends on the share of applied knowledge not directly used in the production of consumer goods. The image of the economic evolution that the model represents is quite realistic.

In the more recent models (Fatas-Villafranca et al. 2011) the mechanism of emergence of GPT depends on the accumulation of a certain amount of knowledge due to the optimal allocation of resources to research. So the different technological eras succeed one another on the basis of the accumulation of good knowledge.

\section{GPT AND ECONOMIC GROWTH: EMPIRICAL EVIDENCE}

GPTs are real engines of growth as with the spread of new general purpose technologies they are adopted by a growing number of industries, with consequent progress that increases productivity growth in the various sectors. Since the use of technology spreads in all sectors of the economy, its effects become significant at the aggregate level, affecting the overall growth of the system (Petsas 2003).

It has been demonstrate that the introduction of a GPT in developing countries allows, temporarily, a gain in competitiveness for marginal industries that produce final goods, even if the process is not destined to last due to the use of technology mainly for the production of intermediate goods (Helpman, Trajtenberg, 1998).

GPTs have the ability to increase labor productivity, as happened with a famous GPT, the steam engine, which had a strong impact on the growth of UK productivity in the nineteenth century, laying the foundations for the 'outbreak' of the first industrial revolution. And the latest information technologies can have an even greater impact on growth, giving rise to the so-called third industrial revolution (Schienstock, 2004).

In the context of the analysis of the effects of GPT on growth, the US case is illuminating, with reference to ICT, considered almost peacefully as general purpose technologies.

Studies at an international level show that the ICT diffusion path is not homogeneous between companies and industries, in time and space. The slowdown in advanced economies, especially in the USA, experienced in the eighties of the last century, followed by an accentuated growth in the following decade can be linked precisely to the increased use of ICT and represents the 'typical' trend of the introduction cycle of a GPT.

The slowdown in economic performance caused by ICT is essentially due to the irreversibility of specific inputs, capital obsolescence and the lack of a suitable workforce to deal with new technology (Helpman, 1998).

Jorgenson et al. (2007) examined the sources of US growth recovery in the 1960-2005 period by identifying the spread of ICT as an important source of capital deepening and the simultaneous growth of factor productivity in the given period. 
Indeed, industries that have expressed greater demand for ICT have also shown growth rates in the productivity of higher factors. In a similar study Basu-Fernald (2007) found the industries in which there was a significant increase in demand and Inklaar-Timmer (2007) compared seven economies in terms of production levels, inputs and multi-factor productivity. The combined analysis of these studies shows that in the USA companies used twice as much ICT than in Anglo-Saxon countries where production was essentially labor intensive, achieving much better results in all sectors.

Jorgenson-Timmer (2011) show, similarly, the rapid growth of productivity in the European Union and Japan, supported by the growing role of the tertiary sector, advanced, by the decrease in the work quota in the definition of the added value, and by the increasing use of ICT in all areas.

With the emergence of ICT and its gradual 'invasion' of all industries, the compensation of skilled workers in this field has increased, as always happens when a GPT is introduced that requires workers with specific skills that are able to convey the introduction of new knowledge in the application sectors, as well as managing it appropriately. These new skills, which are indispensable for GPT to be able to fully express their potential, are for the most part obtained through investments in education and vocational training.

The evident importance of GPT lies in the idea, supported on an empirical level, that the diffusion of a technology with these characters allows to achieve superior performance at the level of industry and of individual companies, as demonstrated by the results of the use of ICT (Majumdar, 2010 ). Radical innovation, like GPT, can change the economic destinies of countries and geographical regions. For example, the arrival of microelectronics and the Internet has shifted economic power from the US east coast to Silicon Valley (Cave, Soheigeartaigh, 2018). The introduction of a GPT, therefore, transforms the economic conditions and the productive processes of many industries, but, as often happens, also the industrial geography.

It is known that productive activities tend to be grouped together in specific places to access external economies, increasing returns to scale, reduction of transaction costs, reduction of learning costs, and further technological development, induced by interaction between companies. This makes the distribution of GPT unequal in space (Porter, 1998).

If the introduction of a GPT "cancels" the specific competences of a sector, thus eliminating the traditional sources of competitive advantage, the geographical area in which the industry is located will suffer a negative shock.

If we study these processes using the product life cycle model, we note how the technologies used by the industry follow trajectories with distinct phases and that each of these phases has a different geography.

At the beginning of the life cycle, when a new market or a new technological opportunity emerges, we are witnessing a phase of experimentation in which companies explore the different methods to exploit these opportunities: this is a phase in which there are strong uncertainties on technology, and on the skills required to succeed on the market. All this leads to a reduction in entry barriers and a possibility, at least potential, of new companies entering the industry (Scott, Storper, 2003).

At the end of this process a dominant standard is established, and industry can develop, in addition to product innovation, also process innovation. At this stage the economies of scale are very important, leading to an industrial and geographical consolidation. In this regard it was argued that 
collaboration in the activity of innovation, and licensing, favor the assertion of a dominant standard, and this emerges with particular relevance for GPT (Liebowitz, Margolis, 1995).

This element is of particular importance for the development of incremental innovative activities, which improve the technology, allowing a better exploitation of the potential. The pervasiveness of the dominant technology remains until all technological opportunities have been fully exploited.

We can expect a path of this type when a new GPT emerges, with an initial geographical volatility, followed by a growing concentration once a new standard has been imposed.

GPTs can benefit from the geographical proximity of research and development with areas where there are valid applications. The geographical proximity between those who develop, those who adopt and those who provide skills for GPT facilitates communication, and reduces the failures of coordination processes, improving the prospects for development of GPT, as well as contributing to the competitive development of the geographical area of reference (Boschma, 2005).

\section{CONCLUSIONS}

Drastic innovations are considered the real engine to activate a lasting growth process. These innovations present a high level of uncertainty, even if, when it is possible to identify their potential, and the breadth of application, they can trigger real 'revolutions'.

Radical innovations make it possible to create new knowledge and develop a wide range of applications even in very different sectors. Radical innovations are often traced back to the concept of general purpose technologies (GPT)

GPTs are real shocks that give new life to the economic system as a whole, and in every economic era we can highlight one or more GPTs that have actually 'upset' the existing paradigm.

GPTs are technologies of general application and are extremely dynamic from a technological point of view. They appear as pervasive of the system, extremely dynamic and complementary

Studies, and empirical evidence, show that GPTs have been, even in recent times, real engines of growth: in fact GPT are adopted by an ever-increasing number of industries, which develop, starting from the core of GPT, specific complementary innovations, which activate a very important mechanism for productivity growth. 
INTERNATIONAL JOURNAL OF ACADEMIC RESEARCH IN BUSINESS AND SOCIAL SCIENCES

Vol. 9, No. 2, Feb, 2019, E-ISSN: $2222-6990$ ๑ 2019 HRMARS

\section{REFERENCES}

Acs Z., Audretsch D. (2003), Handbook of Entrepreneurship Research, Dordrecht: Kluwer Academic Publichers

Anghion, H. (1998). On the Macroeconomic Effects of Major Technological Change, in General Purpose Technologies and Economic Growth, edited by E.Helpman, 121-144, Cambridge, MA, MIT Press

Arrow, K. (1962), Economic Welfare and the Allocation of Resources for Invention in Nelson R.R., ed The rate and Direction of Inventive Activity. Princeton: Princeton University Press, 609-626

Arthur, W.B. (1989), Competing Technologies, Increasing Returns and Lock-in by Historical Events, Economic Journal 99, 11-31

Basu, S., Fernald, J., (2007), Information and Communications Technology as a General Purpose Technology: Evidence from US Industry Data, German Economic review, 8(2), 146-173

Beaundry, P., Doms, M., Lewis, E., (2010), Should the Personal Computer be Considered a Tecnological Revolution? Evidence From US Metropolitan Areas, Journal of Political Economy 118(5), 988-1036

Boschma, R. (2005), Proximity and Innovation: A Critical Assessment, Regional Studies 39(1), 61-74

Breshnahan, T. (2012), Generality, Recombination and Re-Use in J. Lerner and S. Stern(eds) The Rate and Direction of Inventive Activity Revisited, 2012, University Chicago Press, 611-656

Breshnahan, T., Trajtenberg, M. (1995), General Purpose Technologies: Engine of Growth?, Journal of Econometrics, 65, 83-108

Bresnahan, T., Yin, P. (2010), Reallocating Innovative Resources Around Growth Bottlenecks, Journal of Econometrics 65(1), 83-108

Carlaw, K.I., Lipsey, R.G. (2002). Externalities, Technological Complementaries and Sustained Economic Growth, Research Policy 31, 1305-1315

Carlaw, K., Lipsey, R. (2006). GPT-Driven, Endogenous Growth, The Economic Journal 116(508), $155-$ 174

Cave, S., SohEigeartaigh, S. (2018). An Al Race for Strategic Advantage: Rethoric and Risks, in AAAI/ACM Conference on Artificial Intelligence, Ethics and Society

Cohen, W., Klepper, S. (1992), The Tradeoff between Firm Size and Diversity in the Pursuit of Technological Progress, Small Business Economics, 4, 1-14

Dabrowska, J., Fiegenbaum, I., Kutvonen, A. (2013), Mapping the Perception and Reality of Open Innovation, International Journal of Innovation Management, 17(6), 1-25

Dahlin, K., Behrens, D.M. (2005), When is a Innovation Really Radical? Defining and Measuring Technological Radicalness, Research Policy, 34, 717-737

David, P. (1987) Some New Standards for the Economics of Standardization in the Information Age, in P.Dasgupta and P., Stoneman (eds) Economic policy and Technological Performance, Cambridge University Press, 206-239

David, P. (1990), The Dynamo and the Computer: a Historical Perspective on the Modern Productivity Paradox, American Economic Review, 80, 355-361

Dosi, G. (1982), Technological Paradigms and Technological Trajectories: a Suggested Interpreatation of the Determinants and Directions of Technical Change, Research Policy, 11(3), 147-162

Einsenhardt, K., Martin, J. (2000), Dynamic Capabilities: What are They?, Strategic Management Journal, 21(11) 
INTERNATIONAL JOURNAL OF ACADEMIC RESEARCH IN BUSINESS AND SOCIAL SCIENCES Vol. 9, No. 2, Feb, 2019, E-ISSN: $2222-6990$ ๑ 2019 HRMARS

Fatas-Villafranca, F., Jarne, G., Sanchez-Choliz, J. (2011), Innovation Cycles and Growth, Journal of Evolutionary Economics, 22(2), 1-27

Hall, B., Trajtenberg, M., (2004), Uncovering GPTs with Patent Data, Technical Report, National Bureau of Economic Research

Helpman, E. (1998), General Purpose Technologies and Economic Growth, Cambridge, MA: MIT Press Helpman, E., Trajtenberg, M. (1998), A Time to Sow and a Time to Reap: Growth Based on General Purpose Technologies, in Helpman(eds) General Purpose Technologies and Economic Growth, MIT Press, Cambridge, MA

Inklaar, R., Timmer, M. (2007), Comparisons of Industry Output, Inputs and Productivity Levels, Economic Systems Research 19(3), 343-363

Jacobs, B., Nahuis, R. (2002), A General Purpose Technology Explains the Solow Paradox and Wage Inequality, Economics Letters, 74(2), 243-250

Jorgenson, D., Ho, M., Samuels, J., Stiroh, K. (2007), Industgry Origins of the American Productivity Resurgence, Economic System Research, 19(3), 229-252

Jorgenson, D., Timmer, M., (2011), Structural Change in Advanced Nations. A New Set of Stylised Facts, The Scandinavian Journal of Economics, 113(1) 1-29

Jovanovic, B., Rousseau, P. L. (2005), General Purpose Technologies, in Anghion P., Durlauf S., (eds) Handbook of Economic Growth, Elsevier 1182-1224

Kamien, M.I., Schwartz, N.L. (1975), Market Structure and Innovation: A Survey, Journal of Economic Literature, 13(1), 1-37

Leifer, R., Christopher, M., McDermott, G., Peters, L.S., Rice, M.P., Veryzer, R.W. (2000), Radical Innovation: How Mature Companies Can Outsmart Upstars, Harvard Business Press

Liebowitz, S.J., Margolis, S.E. (1995), Path Dependance, Lock-in and History, Journal of Law, Economics and Statistics 17(6), 105-115

Lipsey, R., Carlaw, K., Bekar, T. (2005), Economic Transformations: General Purpose Technologies and Long Term Economic Growth, Oxford University Press, Oxford

Nelson, R. (1959), The Simple Economics of Basic Scientific Research, Journal of Political Economy, 67, 297-307

Majumdar, S. (2010), Fiber in the Backbone! The Impact of Broadband Adoption on Firm Growth in Network Markets, Economics of Innovation and New Technology, 19(3), 283-293

Mokyr, J. (1990), Punctuated Equilibria and Technological Progress, The American Economic Review 80(2), 350-354

Park, J., Shin, S.K., Sanders, G.L. (2007) Impact of International Information Technology Transfer on National Productivity, Information System Research, 18(1), 86-102

Petsas, I. (2003). The Dynamic Effects of General Purpose Technologies on Shumpeterian Growth, Journal of Evolutionary Economics, 13, 577-605

Porter, M.E. (1998). Clusters and the New Economics of Competition, 76, Harvard Business Review Boston

Rosenberg, N., Trajtenberg, M. (2004). A General-purpose Technology at Work: The Corliss Steam Engine in the Late-nineteenth-century United States, The Journal of Economic history, 64(1), 61-99

Rubera, G., Kirca, H. (2012). Firm Innovativeness and Its Performance Outcomes; A Meta-Analytic Review and Theoretical Integration, Journal of Marketing 76(2), 130-147 
Schienstock, G. (2004). Embracing the Knowledge Economy: The Dynamic Transformation of the Finnish Innovation System, Edward Elgar Publishing

Schumpeter, F.A. (1934). The Theory of Economic Development; an Inquiry into Profits, Capital, Credit, Interest and the Business Cycle, Cambridge: Harvard University Press

Scott, A., Storper M. (2003). Regions, Globalization, Development, Regional Studies, 37(6-7), 579-593 Trott, P. (2009). Innovation Management and New Product Development, R\&D Management, 39(2), 226-228

Van Zon, A., Fortune, E., Kronenberg, T. (2003). How to Sow and Reap as You Go: a Simple Model of Cyclical Endogenous Growth, MERIT Research Memoranda 